\title{
Habitat preferences of edible dormouse, Glis glis italicus: implications for the management of arboreal mammals in Mediterranean forests
}

\author{
Mélanie MARTEAU ${ }^{1}$ and Maurizio SARÀ ${ }^{2 *}$ \\ ${ }^{1}$ Rue Jean Giraudoux, Pellevoisin, France \\ ${ }^{2}$ Department of Biological, Chemical Pharmaceutical Sciences and Technology, Palermo University, Italy; \\ e-mail:maurizio.sara@unipa.it
}

Received 15 October 2014; Accepted 17 April 2015

\begin{abstract}
Research on arboreal mammals living in Mediterranean forests is poor. Molecular research assessed the existence of an evolutionary significant unit in the edible dormouse populations living in south Italy, Sicily and Sardinia, and we decided to investigate the environmental factors capable of explaining its occurrence and abundance in Sicily, for a better management of these populations. We assessed the species habitat preferences by setting 25 large and 25 small nestboxes in five sample areas along an altitudinal gradient of the Madonie Range, and recorded habitat variables, food availability, and demographic data for two years. To obtain synthetic descriptors of the dormice habitat requirements, we extracted uncorrelated linear combinations of original variables by Principal Component Analysis; then we modelled habitat preferences of dormice by Generalized Linear Models, and selected the best models by Akaike's information criterion and model averaging. Dormice abundances varied markedly between the two years of study. Population peaked and reproduced in 2010, a masting year of oaks and beeches. In the following non-masting year, a much lower number of adults and yearlings used nestboxes, without any sign of reproduction. In both years we found a significant effect of altitudinal vegetation belt. Dormice seem to prefer mixed broad-leaved and evergreen (cork, holm) oak forests below 800-1300 m a.s.l, to beech forests at higher altitude, and avoid coniferous plantations. Inside these woodlands they seem to prefer monotypic and mature oak-stands with dense canopies. Large nestboxes are more preferred than small ones only during reproductive years. Protection of large and mature woodland from wildfires and forestry management caring the retention of significant elements like old trees, logs and litter mounds are necessary to maintain the habitat of edible dormouse in Southern Mediterranean forests. Artificial nestboxes are a viable device to help population restocking in degraded forests.
\end{abstract}

Key words: Generalized Linear Model (GML), information theoretic approach, Akaike Information Criterion (AIC), artificial nest boxes, arboreal species conservation

\section{Introduction}

In fast changing landscapes, modelling environmentspecies relationships is one of the main goals of ecological research aiming at a balance between conservation and the increasing demand of natural resources (Rushton et al. 2004). Habitat preference and distribution models referred to appropriate spatial-scales, are increasingly being used to address a wide range of questions in ecology and conservation (Lehmann et al. 2002, Araújo \& Guisan 2006), like primary information for identification of conservation hotspots (Ortega-Huerta \& Peterson 2004), regional conservation planning and reserve design (Li et al. 1997, Özesmi \& Mitsch 1997, Mace et al. 1999). Major goal of such modelling is to search for anthropogenic drivers (e.g. deforestation, land use change), abiotic (e.g. topography, climate) factors, biotic interactions (e.g. dispersal or competition), as well as historical and contingent factors that shape species distributions; aiming at the selection of the "best" model for each species in terms of predictive accuracy (e.g. Pearce et al. 2001, Cabeza et al. 2004, Claridge et al. 2008, López-Iborra et al. 2011). Studies modelling the habitat preference of species commonly follow a correlative approach based on multiple regression methods (e.g. Generalized Linear Models) to combine species' occurrence data with environmental conditions where a species is known to be present or absent and then to build a representation of a species' ecological requirements (Guisan \& Zimmermann 2000, Bolker et al. 2009, Franklin 2009). The information theoretic (IT) approach represents the most recent advance in this field (Grueber et al. 2011). 
Often authors refer to habitat selection and habitat preference as they were equivalent (e.g. Berg \& Berg 1998, Suárez-Seoane et al. 2002, Jeganathan et al. 2004). We prefer to make a distinction between habitat selection, the behavioural process with which individuals choose resources, and habitat preference, i.e. the final pattern of habitats used with respect to their availability (Manly et al. 2002, Martínez et al. 2003). In addition, habitat preferences have been assumed to be adaptive (Martin 1998), as they involve a hierarchical discrimination of environmental features that provide the use of different pattern of resources, which in turn affect survival and reproduction of animal species. We therefore referred our research in terms of habitat preference, because we aimed to determine the habitat features on which the settlement of our focal species (the edible dormouse, Glis glis) depends in a Mediterranean forest, and whether habitat requirements are the same between different age cohorts of individuals.

The phylogeography of glirids (Hürner et al. 2010, Lo Brutto et al. 2011, Mouton et al. 2012, Perez et al. 2013) has been recently analysed in the Palaearctic by mitochondrial DNA analyses. Results on edible dormouse (Hürner et al. 2010) have revealed two different lineages, namely the European and Italian lineage. A further analysis on nuclear DNA (Hürner et al. in lit.) has definitely confirmed the genetic separation of the South Italian population (Calabria, Eolian islands, Sardinia and Sicily), therefore supporting the validity of the G. g. italicus subspecies. Actually, only few researches have addressed habitat preferences of arboreal rodent species in forests of northern (Berg \& Berg 1998, Lurz et al. 2000, Wolton 2009, Suzuki et al. 2013) and southern Palaearctic (Cagnin et al. 2000, Bertolino \& Di Montezemolo 2007). Very few information about the ecology of $G$. g. italicus in peninsular Italy (Franco 1990, Capizzi et al. 2003) and Sicily (Milazzo et al. 2003) is available, and modelling on edible dormice habitat preferences in Mediterranean forests is totally lacking. Therefore, we started an investigation along an altitudinal gradient, aiming to discriminate the environmental factors capable of explaining the occurrence and abundance of this subspecies in woodlands of Sicily. We examined whether habitat preferences changed by age and reproductive performance of the population, comparing a year with reproduction $(2010)$ to one without reproduction (2011). Eventually, our findings could support the best management practices for arboreal species living in forested protected areas of the Mediterranean region.

\section{Material and Methods}

Study area

In northern Sicily, the Madonie mountain range, within a Natural Regional Park of some 40000 ha $\left(37^{\circ} 50^{\prime} \mathrm{N}-14^{\circ} 05^{\prime} \mathrm{E}\right)$ is a dolomite massif which vegetation is arranged along several altitudinal belts. At higher altitudes (2000-1300 $\mathrm{m}$ a.s.1.), the massif is characterized by beech forests (Anthrisco-Fagetum aceretosum) of the Sub-Atlantic belt: this forest extends down to mixed broad-leaved oak forests (1300-800 m a.s.1.) and then to the low-altitude (800-50 $\mathrm{m}$ a.s.1.) mixed evergreen oak woodlands (Erico-Quercion ilicis) of the Mediterranean belt (Pignatti 1997, Raimondo 1998). Evergreen woodland is dominated by cork oaks (Quercus suber and/or Q. ilex), often intermingled with broad-leaved oaks ( $Q$. virgiliana, $Q$. amplifolia and $Q$. delechampi), ashes (Fraxinus ornus) and pines (Pinus pinea). The undergrowth layer is mainly composed of Erica arborea, Arbutus unedo, Cistus creticus, C. monspeliensis, $C$. salvifolius, and Calicotome infesta (Raimondo 1998). These areas of the Natural Park, extending for approximately 4000 ha, plus further 6500 ha of low and high shrubland and degraded woods are particularly hit by humaninduced fires and are classified as high or very high risk of fire (USSAB 2003). Most of Madonie woodlands, including the sample areas were coppiced until the 1950-60, a management which has now stopped. They are actually subjected to limited local logging and anti-wildfire management with removal of dead wood, understorey and other high flammable materials.

During April-December of 2010 and 2011, field sampling of edible dormouse (Glis glis) was carried out in 1-ha grid areas provided with artificial nestboxes and representative of altitudes and vegetation compositions in the Madonie Regional Park (Fig. 1). Inside each area, 10 sampling plots $(10 \times 10 \mathrm{~m})$ were centred on the grids for sampling vegetation.

\section{Study species}

The edible dormouse is a small (head-body length $=$ 129-215 mm, weight $=78-243 \mathrm{~g}$, Capizzi \& Filippucci 2008) nocturnal rodent, which is distributed from the Baltic Sea to the Mediterranean peninsulas including Sicily, and from the Iberian region to Russia and the Black Sea coasts (Kryštufek 2010). It is an arboreal species which lives on the canopy of mature broadleaved and mixed woodlands, but can be found also in Mediterranean habitats like high maquis and shrubby vegetation in rugged lands of Southern Europe (Capizzi \& Filippucci 2008). Edible dormice are 


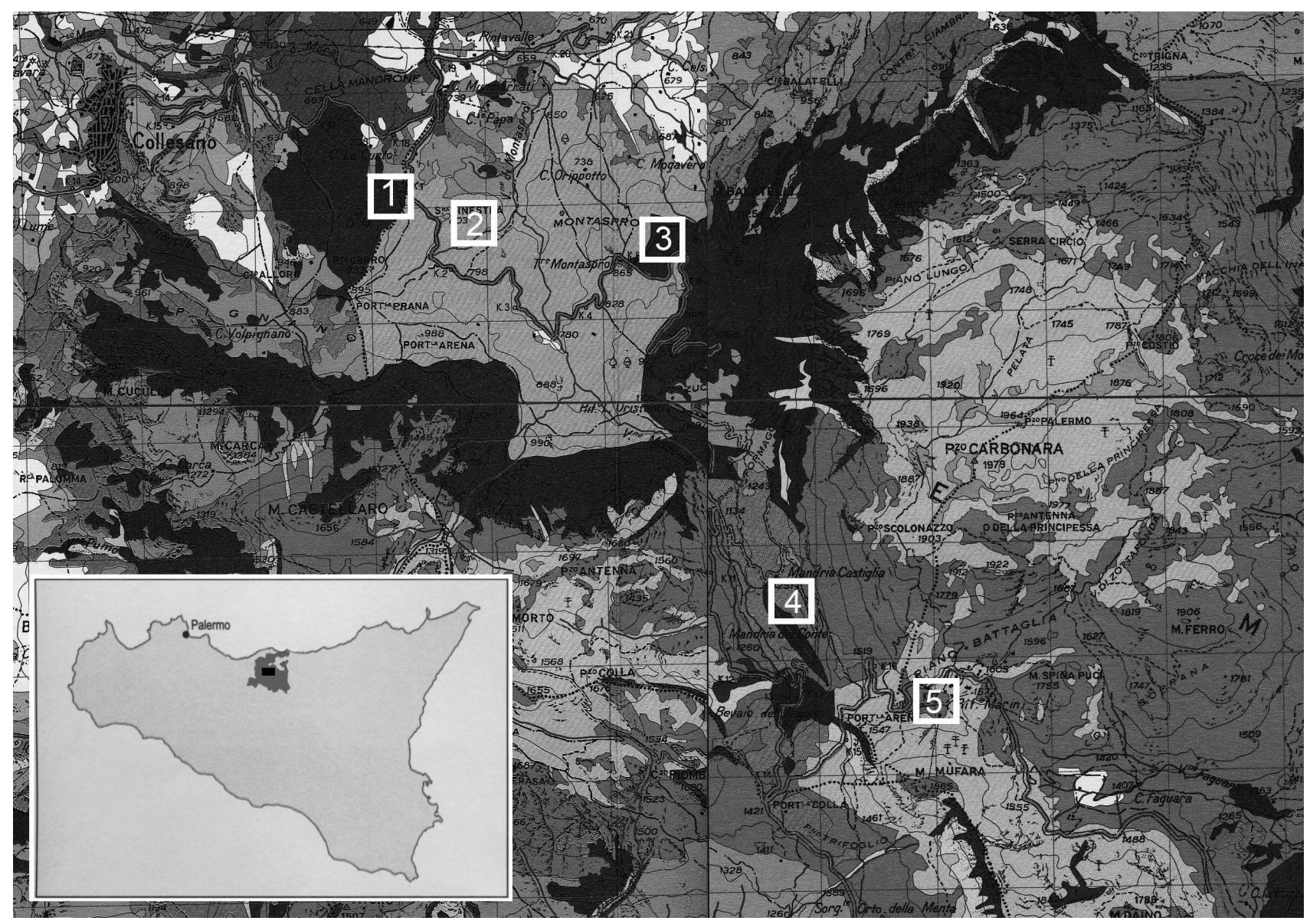

Fig. 1. Main features of the study areas in the Madonie Regional Park (Sicily). 1 - Munciarrati, $710 \mathrm{~m}$ a.s.l., $37^{\circ} 55^{\prime} \mathrm{N}-13^{\circ} 57^{\prime} \mathrm{E}-$ prevalence of Quercus suber, 2 - Serra Ginestra, 790 m a.s.I., $37^{\circ} 54^{\prime} \mathrm{N}-13^{\circ} 58^{\prime} \mathrm{E}$ - mix oak forest of Quercus ilex, Q. suber and Q. pubescens; 3 - Piano Torre, $865 \mathrm{~m}$ a.s.I., $37^{\circ} 54^{\prime} \mathrm{N}-13^{\circ} 59^{\prime} \mathrm{E}$ - prevalence of Quercus ilex; 4 - Piano Zucchi, $1170 \mathrm{~m}$ a.s.I., $37^{\circ} 53^{\prime} \mathrm{N}-14^{\circ} 0^{\prime}$ $\mathrm{E}$ - pine trees (reforestation); 5 - Piano Battaglia, $1530 \mathrm{~m}$ a.s.I., $37^{\circ} 52^{\prime} \mathrm{N}-14^{\circ} 0^{\prime} \mathrm{E}$ - Fagus sylvatica forest.

gregarious animals (Kryštufek 2010), in spring males may use huddling behaviour as a mechanism for social thermoregulation (Fietz et al. 2010) and cases of communal breeding of females have been recorded (Pilastro 1992, Koppmann-Rumpf et al. 2012). During winter the edible dormouse can spend 6-8 months hibernating in communal underground burrows (Vietinghoff-Riesch 1960, Vogel 1997). Adults have small home-range sizes $(<1-7 \mathrm{ha})$, with males having larger home ranges than females (Morris \& Hoodless 1992, Scinski \& Borowski 2008) and high site fidelity (Kryštufek 2010), suggesting that dispersal occurs during the juvenile/yearling stage (Ruf et al. 2006, Bieber \& Ruf 2009a). Edible dormice have only one litter per year, with a mean litter size of 5.5 young (Pilastro et al. 2003, Lebl et al. 2010). The mean life expectancy of edible dormice varies (2.4-5.6 years) among investigated populations (Lebl et al. 2011). All those features limit the potential suite of available habitats and make edible dormouse highly sensible to habitat fragmentation (Mortelliti et al. 2009).

\section{Population sampling}

After preliminary inspection in the Natural Park, five areas representative of the altitudinal belts of vegetation were selected. In each area, five large nestboxes (40 $\times 30 \times 30 \mathrm{~cm}$, with diameter of entrance hole: 50 $\mathrm{mm})$ and five small nestboxes $(30 \times 25 \times 25 \mathrm{~cm}$, with diameter of entrance hole: $32 \mathrm{~mm}$ ) were installed in April 2011 in two separate grids. Each grid formed a square of one hectare, with four nestboxes, spaced at least $50 \mathrm{~m}$ one from another, placed in each corner of the square, and a fifth nestbox placed in the middle of the square. In every sample area, the two grids were distant at least $100 \mathrm{~m}$ each other. All nestboxes were mounted on trees at 4-6 $\mathrm{m}$ above the ground with the aid of ladders, and with the entrance hole facing the tree trunk to facilitate dormice colonization (Morris et al. 1990). Inspections were carried out with a monthly schedule for checking the animal presence and activity inside nestboxes; except for the reproduction period, in which two visits per month were made. Sex, status of reproduction, biometric data (body-weight, body 
Table 1. List of the 45 variables used to characterize the habitat structure in the five sampling areas of the Madonie Regional Park. All measures expressed in $\mathrm{cm}$, except acorn biomass $(\mathrm{g})$.

\begin{tabular}{|c|c|}
\hline Variables & Definition \\
\hline \multicolumn{2}{|l|}{ Ground characteristics } \\
\hline $\log$ & Number of logs and branches with diameter $>10 \mathrm{~cm}$ \\
\hline Stem & Number of stems \\
\hline Rock & Number of rocks \\
\hline Litter & Percentage of litter cover \\
\hline Herb & Percentage of herbaceous and low shrub cover \\
\hline \multicolumn{2}{|l|}{ Nest structure } \\
\hline NestDBH & Diameter at breast height of the tree where the nestbox was placed \\
\hline NestHeight & Height of the tree where the nestbox was placed \\
\hline NestSpecies & Species of the tree where the nestbox was placed \\
\hline \multicolumn{2}{|c|}{ Vertical Habitat Structure } \\
\hline CanopyOpen & Percentage open sky \\
\hline LAI4ring & Leaf Area Index (LAI) integrated over the zenith angles 0 to $60^{\circ}$ \\
\hline LAI5ring & Leaf Area Index (LAI) integrated over the zenith angle 0 to $75^{\circ}$ \\
\hline MeanDBH & Average diameter of trees $(\mathrm{DBH})$ \\
\hline MinDBH & Minimum diameter of tree \\
\hline MaxDBH & Maximum diameter of tree \\
\hline $\mathrm{SdDBH}$ & Standard deviation of the diameter of trees \\
\hline TreeDensity & Average number of trees \\
\hline MeanHeight & Average height of trees \\
\hline MinHeight & Minimum height of tree \\
\hline MaxHeight & Maximum height of tree \\
\hline SdHeight & Standard deviation of the height of trees \\
\hline NTSpecies & Number of trees species \\
\hline ShannonIndex & Diversity of trees according to Shannon index \\
\hline DomSpecies & Dominant species of trees \\
\hline PercentDomSpecies & Percent of dominant species of trees \\
\hline Holes & Total number of holes in trees \\
\hline Ivy & Number of trees with ivy \\
\hline \multicolumn{2}{|l|}{ Habitat structure } \\
\hline Altitude & Altitude above sea level \\
\hline WoodType & Vegetation association \\
\hline Crop & Average acorn biomass \\
\hline AnnualMeanT & Annual average temperature $\left({ }^{\circ} \mathrm{C}\right)$ \\
\hline AnnualSdT & Standard deviation of the annual average temperature \\
\hline CMMeanT & Average temperature of the coldest month \\
\hline CMSdT & Standard deviation of temperature of the coldest month \\
\hline WMMeanT & Average temperature of the warmest month \\
\hline WMSdT & Standard deviation of the temperature of the warmest month \\
\hline MaxT & Maximum annual temperature \\
\hline MinT & Minimum annual temperature \\
\hline AnnualMeanRH & Annual average relative humidity \\
\hline AnnualSdRH & Standard deviation of the annual relative humidity \\
\hline CMMeanRH & Average relative humidity of the coldest month \\
\hline CMSdRH & Standard deviation of the relative humidity of the coldest month \\
\hline WMMeanRH & Average relative humidity of the warmest month \\
\hline WMSdRH & Standard deviation of relative humidity of the warmest month \\
\hline MaxRH & Maximum relative humidity \\
\hline MinRH & Minimum relative humidity \\
\hline
\end{tabular}


length from snout to anus, tail, ear and tarsus lengths, testis size) of animals found inside the nests have been recorded. A BackHome microchip with unique numeric code (BackHome BioTec ${ }^{\mathrm{TM}}$, Virbac) was inserted under the skin of each captured individual with a sterile veterinary syringe, in order to identify the recaptured animals by a microchip reader. Three age classes were separated, distinguishing between: i) weaned and independent juveniles dormice that were born within the respective year, ii) yearlings that have overwintered only once, and iii) adults that had overwintered at least twice. Adults were differentiated from yearlings by their body size (Schlund 1997, Lebl et al. 2010). For statistical purposes, juveniles and yearlings were treated together in a single "immature" class.

\section{Habitat variables}

A preliminary inspection of habitat variables considered in ecological studies on glirids (Dueser \& Shugart, Jr. 1978, Bright \& Morris 1990, Coppeto et al. 2006, Panchetti et al. 2007), allowed selecting and recording in the field 45 explanatory variables (Table 1). Diameter at breast height (DBH) of the tree supporting the nestbox (hereafter the nest-tree) and of other ten trees chosen at random inside the $10 \mathrm{~m}$ radius around the nestbox were measured as proxy of tree size of each plot (Dueser \& Shugart, Jr. 1978). Heights of the nest-tree and of other ten trees in the $10 \mathrm{~m}$ radius around the nestbox were measured with an inclinometer (TruPulse ${ }^{\mathrm{TM}} 200 \mathrm{~B}$, Laser Technology ${ }^{\mathrm{INC}}$ ); in the case of dense stands such measure was standardized to the top of nearby trees. Furthermore, the number of rocks, logs and stems were counted in a $10 \mathrm{~m}$ radius on the ground around the nest-tree. Tree, shrub and vegetation taxonomic diversities were calculated by the Shannon index (Magurran 1988). The average acorn and beechnut biomass was estimated at each visit collecting all acorns and nuts for five minutes in at least two random squares of $1 \times 1 \mathrm{~m}$ set on the ground below each nest-tree, and then counting and weighing all fruits in laboratory. Altitude of sample area was recorded by an altimeter and wood type was assessed by vegetation maps (Pignatti 1997, Raimondo 1998). The canopy and the structure of the sample grids were analyzed by taking five hemispherical photographs centred at each nest-tree site. We used a Canon digital camera 5D with a hemispherical lens (Walimex Pro $8 \mathrm{~mm} \mathrm{f3.5}$ fisheye) fixed at $1.5 \mathrm{~m}$ above the ground (breast height of the operator). The first photograph was directed towards the top of the canopy and four others were directed to the cardinal directions from the nest-tree. Digital photographs were processed by Gap Light Analyzer 2.0 (GLA, Frazer et al. 1999, 2001). The five photographs measured: i) the percentage of canopy openness, ii) the effective leaf area index (LAI) integrated over the zenith angles from $0^{\circ}$ to $60^{\circ}$ (LAI4ring), and iii) the LAI integrated over the zenith angles from $0^{\circ}$ to $75^{\circ}$ (LAI5ring). The two latter measured the canopy density at different zenith widths (Frazer et al. 1999). Colour lateral photographs were then transformed in black and white by Adobe Photoshop 12.0. This allowed to clearly distinguish vegetation structure in each picture and to estimate by GLA 2.0, the percent of black and white pixels corresponding to: i) tree density (i.e. the count of trees trunks), ii) cover of litter, and iii) cover of herbaceous plus low shrub vegetation.

Ambient temperature $\left({ }^{\circ} \mathrm{C}\right)$ and relative humidity $(\mathrm{RH})$ were recorded in each grid of sample area mounting on trees two HOBO U10-003 Dataloggers (Onset

Table 2. Tukey HSD post hoc test of ANOVA interactions between area and nestbox size. Areas are numbered from 1 to 5 and nestbox size is large (L) or small (S). Table reports the significance p-levels of pair-wise comparisons among areas and sizes and reads as follow: the number of captured dormice does not differ in small boxes of area 1 (1_S, second column) with respect to those captured in all the other small and large areas (rows 2-9). Statistical significance is marked in bold.

\begin{tabular}{|c|c|c|c|c|c|c|c|c|c|}
\hline Area_Box size & $1 \_\mathrm{L}$ & 1_S & 2_L & 2_S & 3_L & 3_S & 4_L & 4_S & 5_L \\
\hline 1_S & 0.947 & & & & & & & & \\
\hline 2_L & 1.000 & 0.947 & & & & & & & \\
\hline 2_S & 0.081 & 0.707 & 0.081 & & & & & & \\
\hline 3_L & 0.707 & 0.081 & 0.707 & 0.001 & & & & & \\
\hline 3_S & 0.366 & 0.985 & 0.366 & 0.999 & 0.005 & & & & \\
\hline 4_L & 0.021 & 0.366 & 0.021 & 1.000 & 0.000 & 0.947 & & & \\
\hline 4_S & 0.012 & 0.248 & 0.012 & 0.999 & 0.000 & 0.870 & 1.000 & & \\
\hline 5_L & 0.324 & 0.976 & 0.324 & 0.999 & 0.004 & 1.000 & 0.963 & 0.901 & \\
\hline 5_S & 0.012 & 0.248 & 0.012 & 0.999 & 0.000 & 0.870 & 1.000 & 1.000 & 0.901 \\
\hline
\end{tabular}


Computer Corporation). Dataloggers were set to record a fix per hour and lasted in place per one year. Data stored in the dataloggers were downloaded by means of the HOBO software and allowed to record and average the climate variables reported in Table 1.

\section{Preliminary analyses}

In Mediterranean woodlands natural hole-trees are a limiting factors for cave-dwellers species (e.g. Sarà et al. 2005) and we used nestboxes of different size as a proxy of large (trees with large holes and nesting chambers) and small (trees with small holes and nesting chambers) breeding space, when modelling habitat preferences. Sizes of nestboxes and entrance holes are critical for selective sampling of arboreal species because favour colonization of a given species respect to another (Morris et al. 1990, Vogel \& Duplain 2012). Nonetheless, small nestboxes were promptly colonized by the edible dormouse, despite their smaller sizes and entrance holes. Dormice did not avoid small entrances as enlarged them by gnawing, so that small nestboxes had an occupation ratio of $52 \%$ (out of $n=25$ ) in the first year and 32 $\%$ (out of $\mathrm{n}=25$ ) in the second year. Edible dormice captured in small nestboxes represented $24.33 \%$ of the total captures and the $21.88 \%$ of the total recaptures in the two years of sampling. Preliminary ANOVAs showed that interaction between area and nestbox size was nearly statistically significant in the case of captures $\left(\mathrm{F}_{(4,40)}=2.528, P=0.057\right)$, and markedly not significant in the case of recaptures $\left(\mathrm{F}_{(4,40)}=1.213, P=0.320\right)$, and Tukey HSD post hoc tests revealed a majority of not significant differences among small and large nestboxes depending from areas (Table 2). Therefore, in some areas the number of captures and recaptures was not different in small and large nestboxes; and in addition, the number of dormice captured or recaptured in the small nestboxes of the richest areas was comparable or even higher to number of capture or recapture in large nestboxes of the poorest areas. Nevertheless, we took care about the nestbox size effect when statistically modelling the habitat preferences of edible dormouse by logistic regressions (see below).

Oak acorns and beechnuts are the major food source of edible dormouse (Pilastro et al. 2003, Ruf et al. 2006) and entire populations can show year-to-year fluctuation in density and skip reproduction in years of non-masting crop of the woodland trees (Pilastro et al. 2003, Ruf et al. 2006, Lebl et al. 2011). Preliminary analysis showed differences in food availability between the two years of study, as mean weight of oak acorns and beechnuts collected below nestboxes in $2010(95.57 \pm 16.78 \mathrm{~g}$, min-max: 0-358.7, $\mathrm{n}=40)$ was significantly different in respect to mean weight of both fruits $(5.63 \pm 1.65 \mathrm{~g}$, min-max: $0-35.9, \mathrm{n}=40)$ in $2011\left(\mathrm{~F}_{(1,78)}=28.474, P=0.00\right)$. Therefore, our sampling covered two seasons: i) 2010, an oak and beech masting year with dormouse reproduction and ii) 2011, an oak and beech non-masting year without reproduction, allowing to test whether habitat preferences changed between the two circumstances. More specifically whether the physio-ecological needs of reproduction required habitat features different from those in a year without reproduction.

As strategy to cope with spurious correlations, i.e. type I errors (Garcia 2004, Roback \& Askins 2005) and multi-collinearity (Draper \& Smith 1981) among variables, we followed the approach of Grosbois et al. (2008) and therefore we divided the explanatory variables in homogeneous subsets (Table 1) and performed separate Principal Component Analyses (PCAs) of each subset. Principal Component Analysis allows combining numerical variables of different kind (e.g. Shannon index, Leaf Area Index, Crop) and Principal Components (PCs) are uncorrelated linear combinations of the original covariates that can be interpreted as synthetic climatic or ecological covariates (Draper \& Smith 1981, Grosbois et al. 2008). For any PCA on a distinct subset, the optimal number of PCs was extracted using the method of cross-validation. In addition, to produce synthetic sets of uncorrelated variables in case of subsets grouping both continuous and categorical variables, we used the PCA-related Hill and Smith method.

\section{Habitat modelling}

Preliminary PCA analyses reduced the group of candidate variables and selected a further set of seven uncorrelated integrative variables (Grosbois et al. 2008), these latter summarized the habitat features available for dormice in the five study areas. To identify the variables that best predicted changes in the abundance of edible dormice, we built logistic regressions based on Generalized Linear Models (GLZ, McCullagh \& Nelder 1989) in which the response variables per every nest box were counts of: i) the number of captured adult males and females (entered in model as "adult"), ii) the number of captured juveniles and yearlings (entered in model as "immature"). We assumed a negative binomial distribution and a log link function for the response variables and we performed independent GLZs per each response variable and year of study. We included 
the integrative habitat variables preliminarily identified by PCAs as fixed continuous factors and nestbox size (large/small $=1 / 0)$ as fixed categorical factor.

Modelling was repeated per every response variable (total adults, and total immature individuals) per two years (2010 and 2011) of sampling, totalling four independent GLZs. We did not consider interactions between predictors or their polynomials to avoid generating sub-models that might be biologically implausible, as well as obtaining potentially spurious results due to the "problem of too many models" (Burnham \& Anderson 2002, Grueber et al. 2011).

To select the best set of variables describing the habitat preferences of dormice in a year of reproduction versus that in a year without reproduction, we used an IT approach for each logistic regression model as described in Grueber et al. (2011). We examined several competing hypotheses simultaneously and identified the best set of models (i.e. hypotheses) by the Akaike Information Criterion (AIC: Akaike 1973, Burnham \& Anderson 2002). We generated the final best subset after having derived all possible combinations (sub-models) from the starting set of integrative variables (i.e. predictors of interest), plus forced us to model the nestbox size as a fixed effect rather than, more properly, as a random effect (Bolker et al. 2009). After having obtained the parameters for all sub-models by using Akaike Information Criterion for small samples (AICc), we used a modelaveraging approach for selecting the top sub-models with similar AICc values. We used the 2AICc cut-off criterion and the zero method for top model averaging (Grueber et al. 2011). The zero method for model averaging is recommended when the aim of the study is to determine which factors have the strongest effect on the response variable (Nakagawa \& Freckleton 2011). That is, we initially yielded as top models all combinations ranked within the $\triangle \mathrm{AICc} \leq 2$ (Burnham $\&$ Anderson 2002). Secondly, a parameter estimate and error of zero was substituted into those models where the given parameter is absent; and finally, the parameter estimate was obtained by averaging over all models in the top model set. The final best subsets therefore contained model-averaged parameters capable of a robust explanation of the abundance of dormice in the study area. All statistical analysis was performed using the software $\mathrm{R}$ version 2.15.3 (www.r-project.org) using ade4, MASS and MuMIn packages.

Table 3. Summary statistics of the independent Principal Component Analyses carried out on four explanatory variable subsets. Ratio is the percentage of variance explained by each PC axis. Representative variables are the raw variables with the highest correlations to PC axes, as indicated by values between parentheses, therefore most contributing to the new integrative variables. Variable names and abbreviations defined as in Table 1.

\begin{tabular}{|c|c|c|c|c|c|}
\hline Subset & $\mathrm{PC}$ axis & Eigenvalue & Ratio (\%) & Representatives variables & Integrative variables \\
\hline Ground characteristics & 1 & 3.09 & 61.8 & $\begin{array}{c}\log (-74.15) \\
\text { Litter }(-81.21)\end{array}$ & Soil (-) \\
\hline \multirow{2}{*}{ Nest structure } & 1 & 1.88 & 27.0 & NestHeight (-77.35) & NestHeight (-) \\
\hline & 2 & 1.10 & 16.7 & NestSpecies (86.19) & NestSpecies $(+)$ \\
\hline \multirow{3}{*}{ Vertical habitat structure } & 1 & 6.21 & 28.2 & $\begin{array}{l}\text { MeanDBH (77.62) } \\
\text { MaxHeight (82.08) }\end{array}$ & Tree age $(+)$ \\
\hline & 2 & 4.01 & 18.2 & ShannonIndex (71.43) & Wood diversity $(+)$ \\
\hline & 3 & 3.52 & 16.0 & LAI5ring $(-73.01)$ & Canopy density (-) \\
\hline Habitat structure & 1 & 13.16 & 59.8 & $\begin{array}{l}\text { Altitude (91.34) } \\
\text { WoodType (100) }\end{array}$ & Vegetation belt $(+)$ \\
\hline
\end{tabular}

the inclusion of the intercept-only model (i.e. the null model); and then by comparing the support of all sub-models to the data (Symonds \& Moussalli 2011). Unfortunately, the handling of random effects in the IT environment, especially when model averaging is employed, is not straightforward, as the best method of estimating AICs, when random effects are included is unclear (Grueber et al. 2011). This

\section{Results}

\section{Preliminary PCA}

Four independent PCAs reduced the 45 raw variables recorded in the field to seven principal components (PCs), i.e. uncorrelated linear combinations of original variables that represented synthetic descriptors of the study area habitats in the Madonie Regional Park. The seven integrative variables and their directions 
(negative or positive) most contributing to every PC formation are reported in Table 3.

\section{Captures and recaptures}

The total number of individuals captured plus those recaptured during the monthly sessions was much higher in 2010 than in 2011. We recorded 414 captures of 281 edible dormice in 2010 and 85 captures of 41 individuals in 2011. The quota of individuals recaptured the same year was $34.5 \%$ in 2010 , and $43.9 \%$ in 2011. Individuals captured in 2010 and recaptured the year after were the $6.6 \%$ of the total number of captures. In 2010, we recorded a significant effect of sample area on the total number of captures $\left(\mathrm{F}_{(4,40)}=9.568, P=0.00002\right)$ and recaptures $\left(\mathrm{F}_{(4,40)}\right.$ $=4.275, P=0.006$ ). Contrary wise to 2011 , when the effect of sample area was not significant on both number of captures $\left(\mathrm{F}_{(4,45)}=2.035, P=0.105\right)$ and recaptures $\left(\mathrm{F}_{(4,45)}=2.447, P=0.06\right)$.

Dormice reproduced in 2010, with at least 23 reproductive females producing 105 juveniles corresponding to a mean litter size of $6.0 \pm 1.73$ (range 3-9, $n=17$ ). No reproduction occurred in the artificial pine sample area and only one litter was recorded in the beech forest. Litter size among the three oak sample areas was statistically not different $\left(\mathrm{F}_{(3,13)}=0.478, P=0.702\right)$. The year after, no sign of reproduction (presence of newborns, juveniles or reproductive females) was recorded in nestboxes of all areas.

\section{Habitat modelling}

We carried out a total of four independent GLZs ( 2 response variables $\times 2$ years); which identified

Table 4. Models selected by the 2AICc cut-off criterion to delineate the top model set for each response variable. For each model, the Akaike Information Criterion corrected for small sample (AICc); number of parameters (df), maximized log-likelihood (LogLik), AICc differences $(\Delta)$ and Akaike weight $(\omega)$ have been reported.

\begin{tabular}{|c|c|c|c|c|c|c|c|}
\hline & Number & Model* & $\mathrm{df}$ & LogLik & $\mathrm{AICc}$ & $\Delta$ & $\omega$ \\
\hline \multirow{3}{*}{ Adult 2010} & 1 & $\mathrm{BS}+\mathrm{C}+\mathrm{NH}+\mathrm{S}+\mathrm{W}$ & 7 & -77.74 & 172.14 & 0 & 0.43 \\
\hline & 2 & $\mathrm{BS}+\mathrm{C}+\mathrm{NH}+\mathrm{S}$ & 6 & -79.39 & 172.73 & 0.59 & 0.32 \\
\hline & 3 & $\mathrm{BS}+\mathrm{NH}+\mathrm{S}+\mathrm{W}$ & 6 & -79.68 & 173.31 & 1.17 & 0.24 \\
\hline \multirow{9}{*}{$\begin{array}{c}\text { Immature } \\
2010\end{array}$} & 1 & $\mathrm{BS}+\mathrm{NH}+\mathrm{S}+\mathrm{WD}+\mathrm{W}$ & 7 & -103.20 & 223.07 & 0 & 0.20 \\
\hline & 2 & $\mathrm{BS}+\mathrm{NS}+\mathrm{WD}+\mathrm{W}$ & 6 & -104.90 & 223.75 & 0.67 & 0.14 \\
\hline & 3 & $\mathrm{BS}+\mathrm{NH}+\mathrm{S}+\mathrm{WD}$ & 6 & -105.11 & 224.16 & 1.09 & 0.11 \\
\hline & 4 & $\mathrm{BS}+\mathrm{NH}+\mathrm{NS}+\mathrm{WD}+\mathrm{W}$ & 7 & -103.82 & 224.31 & 1.24 & 0.11 \\
\hline & 5 & $\mathrm{BS}+\mathrm{NH}+\mathrm{NS}+\mathrm{WD}$ & 6 & -105.29 & 224.52 & 1.45 & 0.10 \\
\hline & 6 & $\mathrm{BS}+\mathrm{NH}+\mathrm{NS}+\mathrm{S}+\mathrm{WD}+\mathrm{W}$ & 8 & -102.51 & 224.52 & 1.45 & 0.10 \\
\hline & 7 & $\mathrm{BS}+\mathrm{NH}+\mathrm{WD}$ & 5 & -106.61 & 224.58 & 1.51 & 0.09 \\
\hline & 8 & $\mathrm{BS}+\mathrm{WD}+\mathrm{W}$ & 5 & -106.69 & 224.74 & 1.66 & 0.09 \\
\hline & 9 & $\mathrm{BS}+\mathrm{NH}+\mathrm{WD}+\mathrm{W}$ & 6 & -105.50 & 224.96 & 1.89 & 0.08 \\
\hline \multirow{3}{*}{ Adult 2011} & 1 & $\mathrm{BS}+\mathrm{S}+\mathrm{W}$ & 5 & -47.90 & 107.16 & 0 & 0.60 \\
\hline & 2 & $\mathrm{BS}+\mathrm{W}$ & 4 & -49.53 & 107.95 & 0.79 & 0.40 \\
\hline & 1 & $\mathrm{NS}+\mathrm{W}$ & 4 & -13.86 & 36.61 & 0 & 0.14 \\
\hline \multirow{10}{*}{$\begin{array}{l}\text { Immature } \\
2011\end{array}$} & 2 & NS & 3 & -15.08 & 36.68 & 0.07 & 0.14 \\
\hline & 3 & $\mathrm{~W}$ & 3 & -15.14 & 36.80 & 0.19 & 0.13 \\
\hline & 4 & (NULL) & 2 & -16.48 & 37.23 & 0.62 & 0.11 \\
\hline & 5 & $\mathrm{C}+\mathrm{NS}$ & 4 & -14.37 & 37.63 & 1.02 & 0.09 \\
\hline & 6 & $\mathrm{C}$ & 3 & -15.60 & 37.72 & 1.11 & 0.08 \\
\hline & 7 & $\mathrm{NS}+\mathrm{TA}+\mathrm{W}$ & 5 & -13.19 & 37.75 & 1.14 & 0.08 \\
\hline & 8 & $\mathrm{TA}+\mathrm{W}$ & 4 & -14.65 & 38.19 & 1.58 & 0.07 \\
\hline & 9 & $\mathrm{NS}+\mathrm{WD}+\mathrm{W}$ & 5 & -13.56 & 38.48 & 1.87 & 0.06 \\
\hline & 10 & $\mathrm{NS}+\mathrm{S}$ & 4 & -14.80 & 38.50 & 1.89 & 0.06 \\
\hline & 11 & $\mathrm{NH}+\mathrm{NS}$ & 4 & -14.84 & 38.57 & 1.97 & 0.05 \\
\hline
\end{tabular}

*Variables included in models: BS = Box size, $\mathrm{C}=$ Canopy density, NH = Nest height, NS = Nest species, $\mathrm{S}=\mathrm{Soil}, \mathrm{TA}=\mathrm{Tree}$ age, WD = Wood diversity, $\mathrm{W}=$ Vegetation belt, Null model $=($ NULL $)$. 
Table 5. Results of model-averaging the edible dormouse habitat preferences in Mediterranean woodlands of Sicily. The effects of each predictor on the abundance of adults and immature dormice in one year with (2010) and one without (2011) reproduction are reported as coefficients (Estimate), unconditional standard error (SE), lower $(\mathrm{L} 95 \% \mathrm{Cl})$ and upper $(\mathrm{U} 95 \% \mathrm{Cl}) 95 \%$ confidence intervals. Predictors whose $95 \%$ confidence intervals do not include zero affect more significantly the abundance of adult and immature dormice, and are marked in bold.

\begin{tabular}{|c|c|c|c|c|c|}
\hline & Predictor & Estimate & $\mathrm{SE}$ & $\mathrm{L} 95 \% \mathrm{CI}$ & $\mathrm{U} 95 \% \mathrm{CI}$ \\
\hline \multirow{6}{*}{ Adult 2010} & Intercept & -0.273 & 0.251 & -0.764 & 0.219 \\
\hline & Box size $(+)$ & 1.162 & 0.272 & 0.629 & 1.695 \\
\hline & Canopy density (-) & -0.474 & 0.218 & -0.901 & -0.048 \\
\hline & Nest height (-) & 0.876 & 0.283 & 0.321 & 1.431 \\
\hline & Soil (-) & -0.477 & 0.206 & -0.881 & -0.073 \\
\hline & Vegetation belt $(+)$ & -0.533 & 0.257 & -1.037 & -0.029 \\
\hline \multirow{7}{*}{ Immature 2010} & Intercept & 0.062 & 0.319 & -0.564 & 0.688 \\
\hline & Box size $(+)$ & 1.510 & 0.412 & 0.703 & 2.317 \\
\hline & Nest height (-) & 0.887 & 0.389 & 0.126 & 1.651 \\
\hline & Soil (-) & -0.602 & 0.286 & -1.162 & -0.042 \\
\hline & Wood diversity $(+)$ & -0.625 & 0.297 & -1.208 & -0.043 \\
\hline & Vegetation belt $(+)$ & -0.658 & 0.297 & -1.240 & -0.076 \\
\hline & Nest species $(+)$ & 0.429 & 0.256 & -0.073 & 0.930 \\
\hline \multirow{4}{*}{ Adult 2011} & Intercept & -29.14 & $2.7 \mathrm{e}^{+05}$ & $-5.3 \mathrm{e}^{+05}$ & $5.3 \mathrm{e}^{+05}$ \\
\hline & Box size $(+)$ & 29.87 & $2.7 \mathrm{e}^{+05}$ & $-5.3 \mathrm{e}^{+05}$ & $5.3 \mathrm{e}^{+05}$ \\
\hline & Soil $(-)$ & -0.677 & 0.372 & -1.436 & 0.082 \\
\hline & Vegetation belt $(+)$ & -0.715 & 0.318 & -1.339 & -0.090 \\
\hline \multirow{8}{*}{ Immature 2011} & Intercept & -2.862 & 0.831 & -4.492 & -1.233 \\
\hline & Nest species (+) & -0.991 & 0.709 & -2.381 & 0.398 \\
\hline & Vegetation belt $(+)$ & -1.235 & 0.994 & -3.183 & 0.713 \\
\hline & Canopy density (-) & -0.824 & 0.643 & -2.084 & 0.436 \\
\hline & Tree age $(+)$ & 1.025 & 0.996 & -0.926 & 2.978 \\
\hline & Wood diversity (+) & 0.416 & 0.573 & -0.708 & 1.540 \\
\hline & Soil (-) & 0.475 & 0.641 & -0.781 & 1.730 \\
\hline & Nest height (-) & 0.411 & 0.597 & -0.760 & 1.582 \\
\hline
\end{tabular}

the habitat requirements of the edible dormouse in 2010 and 2011, thanks to the model-averaging method and the 2AICc cut-off criterion. Adult and immature edible dormice do not have the same habitat preferences within the same year and also in a year with reproduction respect to one without reproduction (Table 4). Parameter estimates of every model are reported in Table 5; they are standardized effect sizes and therefore comparable on the same scale.

During the masting year with reproduction (2010 - Table 3), Box size, Nest height, Canopy density, Vegetation belt and Soil were selected as habitat preference predictors for adult dormice with an $\omega$ Akaike weight of 0.43 . The second and third topranked models excluded Vegetation belt and Canopy density, with $\omega$ weights of 0.32 and 0.24 , respectively. The estimates of the five predictors were all negative but the positive Box size and Nest height, they should combine with the directions of integrative variables from PCAs, to have in turn the effects on the response variable (Table 5). Predictors on the number of adults recorded in 2010 thus would indicate more dormice recorded in large nestboxes mounted in short trees and placed in dense canopies with more logs and litters on the ground of oak woodlands (numbered as lower belts).

The 2AICc cut-off criterion yielded nine models predicting immature abundance in 2010. Box size, Nest height, Wood diversity, Vegetation belt and Soil were selected as the first ranked model with a $\omega$ weight of 0.20 ; the second ranked dropped the Soil and Nest height variables and added the Nest species one, yielding a $\omega=0.14$. The following models from third to ninth rank were combination of the above variables, with decreasing weights. In the case of immature dormice, the negative effect of Wood 
Table 6. Summary of the relative importance of variables predicting the presence of edible dormice in Mediterranean woodlands of Sicily. Relative importance of each parameter is the sum of the Akaike weights over all the selected models in which the parameter of interest appears.

\begin{tabular}{|c|c|c|c|c|c|}
\hline Integrative variable & Habitat variable & Adult 2010 & Immature 2010 & Adult 2011 & Immature 2011 \\
\hline Box size & & 1 & 1 & 1 & \\
\hline Vegetation belt & $\begin{array}{c}\text { WoodType } \\
\text { Altitude }\end{array}$ & 0.68 & 0.70 & 1 & 0.48 \\
\hline Nest height & NestHeight & 1 & 0.77 & & 0.05 \\
\hline Nest species & NestSpecies & & 0.44 & & 0.62 \\
\hline Soil & $\begin{array}{c}\text { Log } \\
\text { Litter }\end{array}$ & 1 & 0.41 & 0.60 & 0.06 \\
\hline Wood diversity & ShannonIndex & & 1 & & 0.06 \\
\hline Canopy density & LAI5ring & 0.76 & & & 0.17 \\
\hline Tree age & $\begin{array}{l}\text { MeanDBH } \\
\text { MaxHeight }\end{array}$ & & & & 0.15 \\
\hline
\end{tabular}

diversity replaced that of Canopy density selected for adults and Nest species entered in the model, although without significant effect. Its positive direction comes out from the large codes assigned to oak species with respect to beeches and other trees. The remaining predictors have similar effects on both adult and immature dormice (Table 5).

There were much less significant predictors during the year without reproduction with respect to the former year, with just two top ranked models. Box size, Soil and Vegetation belt were the first ranked model with a weight of 0.60 . Box size and Woodland were the second with a weight of 0.40 (Table 4). However, Vegetation belt was the only significant variable predicting adult presence in 2011 (Table 5). Interestingly, the effect of box size is not significant indicating any strict preference for large nestboxes in 2011. As matter of fact this effect is biased, as recorded by the extreme confidence intervals (Table 5), indicative of convergence failure for that model (Bolker et al. 2009).

In the case of immature dormice recorded in 2011, eleven models including the null (i.e. intercept-only model) were ranked within the 2AICc points (Table 4). Their Akaike weights were correspondently small, with the first and second ranked model both yielding a weight of 0.14 . Nest species plus Vegetation belt, and Nest species or Vegetation belt alone were the first three ranked models. None variable has been selected as significant predictor for immatures (in this case only yearlings for the lack of juveniles), nonetheless among the selected variables the positive effect of tree age and wood diversity on yearling presence should be remarked (Table 5); a result which is probably related to yearling dispersal.
The relative importance of variables selected by model averaging is reported in Table 6 and allow cross-comparisons between years and age classes of dormice. Box size has always the highest relative importance $(\mathrm{RI}=1)$ respect to other predictors in all the modelling subsets in which was selected. The immature class in 2010 has been formed grouping juveniles and yearlings, whereas in 2011 it was composed only by yearlings, because dormice did not reproduce. Some caution should be taken as we have cumulated two age-classes with different ecology and habitat preferences due to computational constraints. Nonetheless, since the birth place is likely to influence more the juvenile than yearlings capture place, it is likely that nest box size has no importance for this latter age-class. Some others variables, like Nest height or Soil have the highest relative importance, anyway showed some variation in their RI levels. For instance, Nest height or Canopy density were more important in years of reproduction than in those without reproduction. Soil was relatively more important for reproductive than for non-reproductive adults ( $R I=1$ and 0.60 , respectively), and for adults than for immature dormice.

\section{Discussion}

We modelled habitat preferences of dormice by summarising habitat variables on PCA axes, so to obtain orthogonal integrative variables on the same scale, and a further model-averaging approach estimated the relative importance of each integrative variable (Grueber et al. 2011). Dormice abundances varied markedly between the two years of study. In the oak and beech masting year of 2010, the population 
peaked and used nestboxes for reproduction in relation to local habitat suitability (Schlund 1997, Juškaitis \& Siozinyte 2008). In the following non-masting year, only a much lower number of adults and yearlings used nestboxes like shelter and roosting site (Fietz et al. 2005), and no sign of reproduction was observed. In non-masting years, acorns and beechnuts are rare or completely absent (Ostfeld \& Keesing 2000), and leaves, flowers and fruits are the only alternative resources for dormice to survive (Fietz et al. 2005). In these years, due to low availability of high energetic food, dormice can skip reproduction to avoid the additional costs of pregnancy and lactation (Bieber 1998, Bieber \& Ruf 2009b). Likewise in our study area, the causal link of the absence of reproduction and the diminution of captures in nestboxes would be the low quantity of food resources available for dormice in 2011 compared to 2010. Our findings confirm also for Mediterranean forests, that dormice synchronize reproduction with mast crops of oak and beech species, as occurs at northern and temperate latitudes (Pilastro et al. 2003, Ruf et al. 2006).

During the masting year we found a significant effect of Vegetation belt on the number of captured individuals. Yet, dormice reproduced more in mixed oak wood than in beech forests. In our dataset dormice populations prefer to establish more in mixed broad-leaved and evergreen oak forests below 800-1300 m a.s.1., than in beech forests at higher altitude, and avoid coniferous plantations. In the Madonie, the beech reaches its southernmost Palaearctic limit (Pignatti 1997) and lives only at high altitudes ( $\geq 1300 \mathrm{~m}$ a.s.1.), where after centuries of logging overexploitation, nowadays it shapes mostly as a structurally simple forest on eroded soils. Different features like temperature, scarcity of food and vegetation structure can thus limit dormice presence in such peculiar forest with respect to the lower altitude mixed oak forests (Milazzo et al. 2003). Indeed, it is not possible to disentangle between the altitude and the vegetation-type effect, as the altitudinal range of beeches in Sicily might mask the habitat preferences of dormice. Nonetheless, in the Italian Alps (Pilastro et al. 2003), dormice are found at low altitude ( $\sim 1000 \mathrm{~m}$ a.s.1.) beech forests, and other studies in Switzerland (Eiberle 1977), Germany (Schlund et al. 1997), Lithuania (Juškaitis \& Siozinyte 2008) and Latvia (Pilats et al. 2009) showed the species' preference for oak broad-leaved forests. The effect of Vegetation belt still maintains in the year without reproduction, as the only significant predictor influencing adult presence. This result and the quota of individuals marked in 2010 and recaptured in 2011 would confirm the presence of nestbox fidelity of edible dormouse within the Madonie oak forests, even in years of food scarcity. A similar result was found in a G. glis population in southwest Germany, where nestbox fidelity was high and movements between woodlands $1 \mathrm{~km}$ apart were rare (Ruf et al. 2006).

In our study we considered box size as a surrogate of breeding/shelter space, therefore testing whether the size of the tree-chamber where to live and reproduce, would predict the number of dormice. The use of such fixed factor in modelling allowed identifying the importance of breeding/shelter space when other habitat features are also included in models. Nestbox size is identified as the strongest predictor only when food resources allow reproduction; with adults and immatures most found in large nestboxes. This would confirm, on one hand, the empirical evidences about the use of appropriate nestbox sizes in sampling design of arboreal species (Morris et al. 1990, Vogel \& Duplain 2012), but raise some doubts about population estimates obtained by using nestboxes of different sizes (e.g. Sevianu \& David 2012). More interestingly, box size did not influence adult and immature captures in 2011. This finding would confirm the primary preference of dormice for a suitable breeding space. Nest chambers inside the trunks and branches of comparable size with large nestboxes can be found only in mature and old forests and might become a limiting factor in Temperate or Boreal forests managed for industrial logging (Ecke et al. 2002, Lampila et al. 2009, Bogdziewicz \& Zwolak 2014), as well as in Mediterranean forests periodically subjected to large summer wildfires (Sarà et al. 2006, Moreira \& Russo 2007). In addition to the destruction of mature stands suitable for dormice reproduction, wildfires promote scrubland expansion; thus increasing habitat fragmentation detrimental for dormice and arboreal rodents (Mortelliti et al. 2009, Zapponi et al. 2013).

According to our modelling, predictors would outline a preference for mixed oak-stands, and the connectivity of canopies can facilitate arboreal movements and provide abundant food (Juškaitis \& Siozinyte 2008, Sevianu \& David 2012). In addition, they seem to prefer plots with more logs and litter, as shown by the Soil integrative variable. Dead wood such as stumps and logs found on the forest floor is a key structural element that is used by a broad spectrum of organisms (e.g. Niemelä et al. 2007) and contributes to soil nutrient cycling (Fateaux et al. 2012), thereby providing indication for preference of late succession woodland stages. 
Contrary wise to other studies in central and northern Europe, that have shown the ecological importance of a well developed shrub layer in forest undergrowth (Ivashkina 2006, Sevianu \& David 2012), in our study area dormice do not use forest plots with dense undergrowth. Furthermore, in our study areas edible dormice would avoid nestbox placed on taller trees; a result contradicting what usually found in other studies on dormice (Schlund et al. 1997, Sarà et al. 2003) and other arboreal species (Suzuki \& Yanagawa 2013). Tall trees can provide safe places for the nests, increasing protection from owls and other predators (Schlund et al. 1997) and there is not evident explanation for such negative preference in the Madonie woodlands. Probably this is an indirect outcome of beech forest and conifer plantation avoidance, as pine and beech trees are relatively taller than oaks. Statistical design controlling sample size of nestboxes at different heights (Sarà et al. 2003) would give proper suggestions.

The edible dormice is rare and of conservation concern in the north of its distribution area (Kryštufek 2010), where the major threats are logging and intensification of agriculture, the abandoning of fruit-tree cultivation and replacement of broad-leaved woodlands with coniferous plantation. In Italy the edible dormouse has been listed as a "least concern" species according to IUCN criteria (Rondinini et al. 2013); nonetheless, the highly genetically differentiated G. g. italicus populations found mostly in Sicily, Sardinia and South Italy (Hürner et al. 2010) represent significant elements of regional biodiversity to be preserved. All intra-specific genetic diversity can be formally delimitated as evolutionary significant unit (Ryder 1986, but see Guia \& Saitoh 2006) and maintained for conservation purposes (Moritz 1994). In addition, populations at range limits may be important for longterm survival and evolution of the species due to their evolutionary potential and adaptation to stressful environmental conditions (Lesica \& Allendorf 1995). Peripheral populations should be managed separately to preserve their local adaptations and this could help the species to recover in case of environmental changes (Lesica \& Allendorf 1995). On the other hand, the high genetic differentiation of southern populations indicates that they are potentially highly vulnerable to population bottlenecks (Hürner et al. 2010) due to habitat fragmentation and artificial barriers construction (Mortelliti et al. 2009). For nonvolant small mammals of the Mediterranean, habitat loss and degradation are the most important threat (Temple \& Cuttlelod 2009) and wildfires represent the major potential source of loss, degradation and fragmentation of evergreen and broad-leaved forests (Moreira \& Russo 2007). Preventive protection of large woodlands from wildfires and forestry management plans (e.g. conversion to high forest) careful of arboreal species inside the sites of community interests and all protected areas are basic actions for maintenance of edible dormice populations in the Mediterranean region. Preventive monitoring of arboreal species before coppicing or logging would avoid to cut and alter (e.g. by dead wood removal) mature woodlots and conserve dormice habitats and woodland biodiversity. Artificial nestboxes set in the field after appropriate design, are not only a tool for studying arboreal rodent ecology, but can be used for recovering populations in intensively logged woodlands and in those degraded after wildfires, or as well for building ecological corridors to reconnect woodland fragments.

\section{Acknowledgements}

We thank G. Ferraro, A. Nuccio, G. Macaluso, G. Agnello who helped during field sampling. This research was supported by a grant of the Madonie Regional Park.

\section{Literature}

Akaike H. 1973: Information theory and an extension of the maximum likelihood principle. In: Petrov B.N. \& Csaki F. (eds.), Second international symposium on information theory. Akademiai Kaido, Budapest: 267-281.

Araújo M.B. \& Guisan A. 2006: Five (or so) challenges for species distribution modelling. J. Biogeogr. 33: 1677-1688.

Berg L. \& Berg A. 1998: Nest site selection by the dormouse Muscardinus avellanarius in two different landscapes. Ann. Zool. Fenn. 35: 115-122.

Bertolino S. \& Di Montezemolo N.C. 2007: Garden dormouse (Eliomys quercinus) nest site selection in an alpine habitat. Ethol. Ecol. Evol. 19: 51-60.

Bieber C. 1998: Population dynamics, sexual activity, and reproduction failure in the fat dormouse (Myoxus glis). J. Zool. Lond. 44: 223-229.

Bieber C. \& Ruf T. 2009a: Summer dormancy in edible dormice (Glis glis) without energetic constraints. Naturwissenschaften 96: 165-171.

Bieber C. \& Ruf T. 2009b: Habitat differences affect life history tactics of a pulsed resource consumer the edible dormouse (Glis glis). Popul. Ecol. 51: 481-492.

Bogdziewicz M. \& Zwolak R. 2014: Responses of small mammals to clear-cutting in temperate and boreal forests of Europe: a metaanalysis and review. Eur. J. Forest Res. 133: 1-11. 
Bolker B.M., Brooks M.E., Clark C.J., Geange S.W., Poulsen J.R., Stevens M.H.H. \& White J.-S.S. 2009: Generalized linear mixed models: a practical guide for ecology and evolution. Trends Ecol. Evol. 24: 127-135.

Bright P.W. \& Morris P.A. 1990: Habitat requirements of dormice Muscardinus avellanarius in relation to woodland management in Southwest England. Biol. Conserv. 54: 307-326.

Burnham K.P. \& Anderson D.R. 2002: Model selection and multimodel inference. A practical information-theoretic approach, $2^{\text {nd }}$ edition. Springer, New York.

Cabeza M., Araújo M.B., Wilson R.J., Thomas C.D., Cowley M.J.R. \& Moilanen A. 2004: Combining probabilities of occurrence with spatial reserve design. J. Appl. Ecol. 41: 252-262.

Cagnin M., Aloise G., Fiore F., Oriolo V. \& Wauters L.A. 2000: Habitat use and population density of the red squirrel, Sciurus vulgaris meridionalis, in the Sila Grande mountain range (Calabria, South Italy). Ital. J. Zool. 67: 81-87.

Capizzi D. \& Filippucci M.G. 2008: Glis glis (Linnaeus 1766). In: Amori G., Contoli L. \& Nappi A. (eds.), Fauna d'Italia - Mammalia II. Calderini, Milano: 381-394.

Capizzi D., Battistini M. \& Amori G. 2003: Effects of habitat fragmentation and forest management on the distribution of the edible dormouse Glis glis. Acta Theriol. 48: 359-371.

Claridge A.W., Tennant P., Click R. \& Barry S.C. 2008: Factors influencing the occurrence of small ground-dwelling mammals in Southeastern Mainland Australia. J. Mammal. 89: 916-923.

Coppeto S.A., Kelt D.A., Van Vuren D.H., Wilson J.A. \& Bigelow S. 2006: Habitat associations of small mammals at two spatial scales in the northern Sierra Navada. J. Mammal. 87: 402-413.

Draper N.R. \& Smith H. 1981: Applied regression analysis series in probability and mathematical statistics, $2^{\text {nd }}$ edition. Wiley, New York.

Dueser R.D. \& Shugart, Jr. H.H. 1978: Microhabitats in a forest-floor small mammal fauna. Ecology 59: 89-98.

Ecke F., Löfgren O. \& Sörlin D. 2002: Population dynamics of small mammals in relation to forest age and structural habitat factors in northern Sweden. J. Appl. Ecol. 39: 781-792.

Eiberle K. 1977: Zur Populationsdynamik des Siebenschläfers (Glis glis) im Lehrwald der ETHZ. Schweiz. Z. Forstwes. 12: 630-645.

Fauteux D., Imbeau L., Drapeau P. \& Mazerolle M.J. 2012: Small mammal responses to coarse woody debris distribution at different spatial scales in managed and unmanaged boreal forests. For. Ecol. Manage. 266: 194-205.

Fietz J., Klose S. \& Kalko E. 2010: Behavioural and physiological consequences of male reproductive trade-offs in edible dormice (Glis glis). Naturwissenschaften 97: 883-890.

Fietz J., Pflug M., Schlund W. \& Tataruch F. 2005: Influences of the feeding ecology on body mass and possible implications for reproduction in the edible dormouse (Glis glis). J. Comp. Physiol. Biochem. Syst. Environ. Physiol. 175: 45-55.

Franco D. 1990: Feeding habits of a dormouse population (Myoxus glis) of the Asiago Plateau (Venetian Pre-Alps). Hystrix 2: 11-22.

Franklin J. 2009: Mapping species distributions: spatial inference and prediction. Cambridge University Press, Cambridge.

Frazer G.W., Canham C.D. \& Lertzman K.P. 1999: Gap Light Analyser (GLA), Version 2.0. Simon Fraser University Burnaby, BC and Institute of Ecosystem studies Millbrook, NY.

Frazer G.W., Fournier R.A., Trofymow J.A. \& Hall R.J. 2001: A comparison of digital and film fisheye photography for analysis of forest canopy structure and gap light transmission. Agric. For. Meteorol. 109: 249-263.

Garcia L.V. 2004: Escaping the Bonferroni iron claw in ecological studies. Oikos 105: 657-663.

Grosbois V., Gimenez O., Gaillard J.-M., Pradel R., Barbraud C., Clobert J., Møller A.P. \& Weimerskirch H. 2008: Assessing the impact of climate variation on survival in vertebrate populations. Biol. Rev. 83: 357-399.

Grueber C.E., Nakagawa S., Laws R.J. \& Jamieson I.G. 2011: Multimodel inference in ecology and evolution: challenges and solutions. J. Evol. Biol. 24: 699-711.

Guia A.P.O. \& Saitoh T. 2006: The gap between the concept and definitions in the evolutionarily significant unit: the need to integrate neutral genetic variation and adaptive variation. Ecol. Res. 22: 604-612.

Guisan A. \& Zimmermann N.E. 2000: Predictive habitat distribution models in ecology. Ecol. Model. 135: 147-186.

Hürner H., Kryštufek B., Sarà M., Ribas A., Ruch T., Sommer R., Ivashkina V. \& Michaux J.R. 2010: Mitochondrial phylogeography of the edible dormouse (Glis glis) in the western Palearctic region. J. Mammal. 91: 233-242.

Ivashkina V.A. 2006: Abundance and activity of the edible dormouse (Glis glis L) in the Zhiguli Mountains (Russia, Middle Volga Region). Pol. J. Ecol. 54: 337-344.

Jeganathan P., Green R.E., Norris K., Vogiatzakis I.N., Bartsch A., Wotton S.R., Bowden C.G.R., Griffiths G.H., Pain D. \& Rahmani A.R. 2004: Modelling habitat selection and distribution of the critically endangered Jerdon's courser Rhinoptilus bitorquatus in scrub jungle: an application of a new tracking method. J. Appl. Ecol. 41: 224-237.

Juškaitis R. \& Siozinyte V. 2008: Habitat requirements of the common dormouse (Muscardinus avellanarius) and the fat dormouse (Glis glis) in mature mixed forest in Lithuania. Ekologia 27: 143-151.

Koppmann-Rumpf B., Scherbaum-Heberer C. \& Schmidt K.-H. 2012: Nestbox sharing of the edible dormouse (Glis glis) during the active season. Peckiana 8: 189-196.

Kryštufek B. 2010: Glis glis (Rodentia: Gliridae). Mamm. Species 42: 195-206.

Lampila S., Wistbacka R., Mäkelä A. \& Orell M. 2009: Survival and population growth rate of the threatened Siberian flying squirrel (Pteromys volans) in a fragmented forest landscape. Ecoscience 16: 66-74.

Lebl K., Bieber C., Adamík P., Fietz J., Morris P., Pilastro A. \& Ruf T. 2011: Survival rates in a small hibernator the edible dormouse: a comparison across Europe. Ecography 34: 683-692.

Lebl K., Kurbisch K., Bieber C. \& Ruf T. 2010: Energy or information? The role of seed availability for reproductive decisions in edible dormice. J. Comp. Physiol. Biochem. Syst. Environ. Physiol. 180: 447-456. 
Lehmann A., Overton M.M. \& Austin M.P. 2002: Regression models for spatial prediction: their role for biodiversity and conservation. Biodivers. Conserv. 11: 2085-2092.

Lesica P. \& Allendorf F.W. 1995: When are peripheral populations valuable for conservation? Conserv. Biol. 9: 753-760.

Li W., Wang Z., Ma Z. \& Tang H. 1997: A regression model for the spatial distribution of red-crown crane in Yancheng Biosphere Reserve. Ecol. Model. 103: 115-121.

Lo Brutto S., Sarà M. \& Arculeo M. 2011: Italian Peninsula preserves an evolutionary lineage of the fat dormouse Glis glis L (Rodentia: Gliridae). Biol. J. Linn. Soc. 102: 11-21.

López-Iborra G.M., Limiñana R., Pavón D. \& Martínez-Pérez J.E. 2011: Modelling the distribution of short-toed eagle (Circaetus gallicus) in semi-arid Mediterranean landscapes: identifying important explanatory variables and their implications for its conservation. Eur. J. Wildlife. Res. 57: 83-93.

Lurz P.W.W., Garson P.J. \& Wauters L.A. 2000: Effects of temporal and spatial variations in food supply on the space and habitat use of red squirrels (Sciurus vulgaris L). J. Zool. Lond. 251: 167-178.

Mace R.D., Waller J.S., Manley T.L., Ake K. \& Wittinger W.T. 1999: Landscape evaluation of grizzly bear habitat in western Montana. Conserv. Biol. 13: 367-377.

Magurran A.E. 1988: Ecological diversity and its measurement. Princeton University Press, Princeton, NJ.

Manly B.F.J., McDonald L.L., Thomas D.L., McDonald T.L. \& Erickson W.P. 2002: Resource selection by animals: statistical design and analysis for field studies, $2^{\text {nd }}$ edition. Kluwer, Dordrecht.

Martin T.E. 1998: Are microhabitat preferences of coexisting species under selection and adaptative? Ecology 79: 656-670.

Martínez J.A., Serrano D. \& Zuberogoitia I. 2003: Predictive models of habitat preferences for the Eurasian eagle owl Bubo bubo: a multiscale approach. Ecography 26: 21-28.

McCullagh P. \& Nelder J.A. 1989: Generalized Linear Models, $2^{\text {nd }}$ edition. Chapman and Hall, London.

Milazzo A., Falletta W. \& Sarà M. 2003: Habitat selection of fat dormouse (Glis glis italicus) in deciduous woodlands of Sicily. Acta Zool. Acad. Sci. Hung. 49: 117-124.

Moreira F. \& Russo D. 2007: Modelling the impact of agricultural abandonment and wildfires on vertebrate diversity in Mediterranean Europe. Landsc. Ecol. 22: 1461-1476.

Moritz C. 1994: Defining evolutionarily significants units for conservation. Trends Ecol. Evol. 9: 373-375.

Morris P.A. \& Hoodless A. 1992: Movements and hibernaculum site in the fat dormouse (Glis glis). J. Zool. Lond. 228: 685-687.

Morris P.A., Bright P.W. \& Woods D. 1990: Use of nestboxes by the dormouse Muscardinus avellanarius. Biol. Conserv. 51 : 1-13.

Mortelliti A., Sanzo G.S. \& Boitani L. 2009: Species' surrogacy for conservation planning: caveats from comparing the response of three arboreal rodents to habitat loss and fragmentation. Biodivers. Conserv. 18: 1131-1145.

Mouton A., Grill A., Sarà M., Kryštufek B., Randi E., Amori G., Juškaitis R., Aloise G., Mortelliti A., Panchetti F. \& Michaux J. 2012: Evidence of a complex phylogeographic structure in the common dormouse Muscardinus avellanarius (Rodentia: Gliridae). Biol. J. Linn. Soc. 105: 648-664.

Nakagawa S. \& Freckleton R.P. 2011: Model averaging missing data and multiple imputation: a case study for behavioural ecology. Behav. Ecol. Sociobiol. 65: 103-116.

Niemelä J., Koivula M. \& Kotze D.J. 2007: The effects of forestry on carabid beetles (Coleoptera: Carabidae) in boreal forests. J. Insect. Conserv. 11: 5-18.

Ortega-Huerta M.A. \& Peterson A.T. 2004: Modelling spatial patterns of biodiversity for conservation prioritization in North-eastern Mexico. Divers. Distrib. 10: 39-54.

Ostfeld R.S. \& Keesing F. 2000: Pulsed resources and community dynamics of consumers in terrestrial ecosystems. Trends Ecol. Evol. 15: 232-237.

Özesmi U. \& Mitsch W.J. 1997: A spatial habitat model for the marsh-breeding red-winged blackbird (Agelaius phoeniceus) in coastal Lake Erie wetlands. Ecol. Model. 101: 139-152.

Panchetti F., Sorace A., Amori G. \& Carpaneto G.M. 2007: Nest site preference of common dormouse (Muscardinus avellanarius) in two different habitat types of Central Italy. Ital. J. Zool. 74: 363-369.

Pearce J.L., Cherry K., Drielsma M., Ferrier S. \& Whish G. 2001: Incorporating expert opinion and fine-scale vegetation mapping into statistical models of fauna distribution. J. Appl. Ecol. 38: 412-424.

Perez G.C., Libois R. \& Nieberding C.M. 2013: Phylogeography of the garden dormouse Eliomys quercinus in the western Palaearctic region. J. Mammal. 94: 202-217.

Pignatti S. 1997: Ecologia del Paesaggio. UTET, Torino.

Pilastro A. 1992: Communal nesting between breeding females in a free-living population of fat dormouse (Glis glis L). Ital. J. Zool. 59: $63-68$.

Pilastro A., Tavecchia G. \& Marin G. 2003: Long living and reproduction skipping in the fat dormouse. Ecology 84: 1784-1792.

Pilats V., Pilate D. \& Dzalba I. 2009: The use of nest boxes to survey marginally distributed fat dormouse Glis glis in Latvia. Acta Univ. Latv. 753: 7-18.

Raimondo F.M. 1998: Carta del Paesaggio e della Biodiversità vegetale della Provincia di Palermo. Quad. Bot. Amb. Appl. 9: 3-160.

Roback P.J. \& Askins R.A. 2005: Judicious use of multiple hypothesis tests. Conserv. Biol. 19: 261-267.

Rondinini C., Battistoni A., Peraonace V. \& Teofili C. 2013: Lista Rossa IUCN dei Vertebrati italiani. www.iucn.it

Ruf T., Fietz J., Schlund W. \& Bieber C. 2006: High survival in poor years: life history tactics adapted to mast seeding in the edible dormouse. Ecology 87: 372-381.

Rushton S.P., Ormerod S.J. \& Kerby G. 2004: New paradigms for modelling species distributions? J. Appl. Ecol. 41: $193-200$. 
Ryder O.A. 1986: Species conservation and systematics: the dilemma of subspecies. Trends Ecol. Evol. 1: 9-10.

Sarà M., Bellia E. \& Milazzo A. 2006: Fire disturbance disrupts co-occurrence patterns of terrestrial vertebrates in Mediterranean woodlands. J. Biogeogr. 33: 843-852.

Sarà M., Falletta W. \& Milazzo A. 2003: The effect of exposure and height of nest-boxes on grid colonization by the common dormouse (Muscardinus avellanarius). Acta Zool. Hung. 49 (Suppl. 1): 167.

Sarà M., Milazzo A., Falletta W. \& Bellia E. 2005: Exploitation competition between hole-nesters (Muscardinus avellanarius Mammalia and Parus caeruleus Aves) in Mediterranean woodlands. J. Zool. Lond. 265: 347-357.

Schlund W. 1997: Length of tibia as a measure of body size for determining the age of edible dormouse (Myoxus glis L). Z. Säugetierkd. 62: $187-190$

Schlund W., Scharfe F., Strauss M.J. \& Burkhardt J.F. 1997: Habitat fidelity and habitat utilization of an arboreal mammal (Myoxus glis) in two different forests. Z. Säugetierkd. 62: 158-171.

Scinski M. \& Borowski Z. 2008: Spatial organization of the fat dormouse (Glis glis) in an oak-hornbeam forest during the mating and post-mating season. Mamm. Biol. 73: 119-127.

Sevianu E. \& David A. 2012: An estimate of population density of the fat dormouse Glis glis, movement and nest cohabitation in two types of forests in the Transylvanian Plain (Romania). Peckiana 8: 11-20.

Suárez-Seoane S., Osborne P.E. \& Alonso J.C. 2002: Large-scale habitat selection by agricultural steppe birds in Spain: identifying species-habitat responses using generalized additive models. J. Appl. Ecol. 39: 755-771.

Suzuki K. \& Yanagawa H. 2013: Efficient placement of nest boxes for Siberian flying squirrels Pteromys volans: effects of cavity density and nest box installation height. Wildlife. Biol. 19: 217-221.

Suzuki K., Sagawa M. \& Yanagawa H. 2013: Nest cavity selection by the Siberian flying squirrel Pteromys volans. Hystrix 24: 187-189.

Symonds M.R. \& Moussalli A. 2011: A brief guide to model selection multimodel inference and model averaging in behavioural ecology using Akaike's information criterion. Behav. Ecol. Sociobiol. 65: 13-21.

Temple H.J. \& Cuttelod A. 2009: The status and distribution of Mediterranean mammals. IUCN, Gland Switzerland and Cambridge, U.K.

USSAB 2003: Carta delle aree a rischio d'incendio. Ufficio Speciale Servizio Antincendio Boschivo, Regione Sicilia, Palermo.

Vietinghoff-Riesch A. 1960: Der Siebenschläfer (Glis glis L). Monographien der Wildsäugetiere, Fisher Verlag, Jena.

Vogel P. 1997: Hibernation of recently captured Muscardinus, Eliomys and Myoxus: a comparative study. Nat. Croat. 6: $217-232$.

Vogel P. \& Duplain J. 2012: Testing the use of two types of nest box by the common dormouse Muscardinus avellanarius. Peckiana 8: $157-165$.

Wolton R. 2009: Hazel dormouse Muscardinus avellanarius (L.) nest site selection in hedgerows. Mammalia 73: 7-12.

Zapponi L., Del Bianco M., Luiselli L., Catorci A. \& Bologna M.A. 2013: Assessing environmental requirements effects on forest fragmentation sensitivity in two arboreal rodents. Mamm. Biol. 78: 157-163. 